\title{
Effects of lift-assist device on trunk and shoulder kinematics
}

\section{Abstract:}

Background: Repetitive handling of heavy concrete blocks has been associated with the risk of low back and shoulder injuries among the masons. Several interventions have been proposed to reduce the risk of musculoskeletal disorders among the masons. A new intervention, a lift-assist handle, was tested in this study. Objective: The effectiveness of the lift-assist handle in masonry work was assessed using the shoulder and low back kinematics during block lifting/lowering tasks performed at two heights. Methods: In a laboratory setting, seven male subjects performed with- and without-lift handle assisted block lifting tasks at two different heights. Optical motion capture system and biomechanical modeling software were used to record and model each dynamic trial. Effect of lifting height and use of a lift-assist handle on range of motion of the shoulder and trunk were tested. Results: The use of lift-assist handle significantly reduced trunk motion and increased shoulder motion. Lifting height had a significant effect on shoulder kinematics only. When height was increased from 17to 29 inches, the ranges of motion of shoulder abduction-adduction and internal rotation significantly increased. Additionally, block lifting/ lowering task duration decreased by $26 \%$ when the lift-assist handle was used. Conclusions: While potential benefits to lower back health were found with the lift-assist handle, increased shoulder motion may increase the risk of shoulder injuries. The findings of this study emphasize the need for an in-depth analysis of assistive devices prior to implementation to ensure that there are no unintended consequences of their use that could negate their benefit.

Key Words: Construction block; Lift-assist handle; Shoulder; Trunk; Kinematics
Suman Kanti Chowdhury,

Christopher W. Moore and

Ashish D. Nimbarte

Industrial and Management Systems Engineering, PO Box 6070, West Virginia University, Morgantown, WV 26506-6107

Corresponding Author:

Dr. Ashish D. Nimbarte Email: ashish.nimbarte@mail.wvu.edu

C 2015 IJOSH All rights reserved.

\section{Introduction}

Work-related musculoskeletal disorders (MSDs) are widespread among construction workers in the United States (US) and worldwide. According to the US Bureau of Labor Statistics (BLS), construction workers are at significant risk of MSDs with nonfatal injury rate of 143.4 (per 10,000 full time workers) compared to 112.4 for all other occupations combined [1]. Among the construction workers, brick/block masons are required to regularly lift and maneuver the heavy blocks weighing from $6 \mathrm{~kg}$ to more than $48 \mathrm{~kg}$ to build and repair walls, floors, partitions, fireplaces, chimneys and other structures[2]. This block lifting task is physically demanding and requires repetitive bending, lifting, and twisting in potentially harsh construction environments [3-5]. In recent years, non-fatal injury rate of 3.4 (per 100 full time workers), which was slightly less than non-fatal injury rate of 3.7 for all construction workers has been observed among the masonry contractors/workers [6-7].

The leading cause of injury among masonry workers is overexertion. In a study by the Center for Construction Research and Training (CPWR), masons had the highest incidence rate of injuries due to overexertion [8]. Sprains, strains, and tears were the most common type of overexertion MSDs with 45.3 per 10,000 full time workers suffering from back injuries that require days away from work [8]. 3.7 for all construction workers has been observed among the masonry contractors/workers [6-7].

The leading cause of injury among masonry workers is overexertion. In a study by the Center for Construction Research and Training (CPWR), masons had the highest incidence rate of injuries due to overexertion [8]. Sprains, strains, and tears were the most common type of overexertion MSDs with 45.3 per 10,000 full time workers suffering from back injuries that require days away from work [8]. In addition to the low back MSDs, shoulder injuries were also found to be prevalent among the masons. A few previous studies have reported that approximately $50 \%$ of masonry/bricklayers complain of shoulder injuries due to repetitive handling of construction bricks/blocks [9 -11]. Several previous studies have already shown that physically demanding tasks such as heavy lifting, working at or above shoulder level, and repetitive movements are associated with low back pain [12-18] and shoulder pain [19-23]. 
Chaffin and Park (1973) established a relationship between the level of peak spinal compression in occupational lifts and low back pain incidence[24]. In a cohort study by Latza et al (2000) on German construction workers, it was found that lifting heavy sandstone building blocks $(7-10 \mathrm{~kg})$ for $2 \mathrm{~h}$ or more was associated with a higher prevalence of low back pain than workers who did not engage in such work[13]. In a longitudinal study on 571 male construction workers, Strumer et al (1997) analyzed the association between job history and low back disorders[25]. The authors found that construction workers who routinely performed bricks/blocks lifting tasks for more than 10 years were 2.5 times more likely to have low back MSD than other construction workers.

Several physical factors such as block weight, frequency of lifting, and block lifting height, were recognized as the probable risk factors for the back and shoulder injuries among masons. Van Dieen and Toussaint (1997) found that higher duration of lifting activities (30 and $120 \mathrm{~min}$ ) and higher lifting frequencies (2 to $12 \mathrm{~min}^{-1}$ ) had significantly escalated the peak spinal compression force (1500 to $4100 \mathrm{~N}$ ) and hence increased the likelihood of low back injury[26]. In a field study by Luttmann et al (1991) awkward posture and lifting height were found to be the contributing factors to back and shoulder injury among the masons[27]. A forward bent position was observed while working on the low wall heights whereas, working at higher wall heights $(100-160 \mathrm{~cm})$ required exertions with arms above the shoulder/ head. Anton et al (2005) also found higher upper back and shoulder muscle activity for masons while working at higher wall height [28]. They also found that muscle activity of upper extremity (forearm flexors and extensors) and back (erector spinae) muscles reduced when light weight block $(11.8 \mathrm{~kg})$ was used compared to standard medium weight block $(16.3 \mathrm{~kg})$. On contrary, Van Der Molen et al (2008) found insignificant effect of block weight ranging from 11 to $16 \mathrm{~kg}$ on productivity, duration or frequency of tasks [29].

Some interventions have been suggested by different studies to reduce the risk of MSDs among the masons. Lighter-weight blocks, adjustable height scaffolding to keep working height between 60 to $90 \mathrm{~cm}$, and use of team-lift when handling heavy blocks are a few examples [3, 5, 10, 28-30]. One recent intervention designed to improve handling of the nominal concrete masonry units (CMU) is the use of lift-assist handle/ device. This handle/device may improve the hand-CMU coupling and the strength capability of the major joints. While improving the coupling and the strength, use of such handle may also affect the posture used to perform the lifting task. In this study, effectiveness of one such lift-assist handle used in masonry work was evaluated. Specifically, the shoulder and low back kinematics during block lifting task performed at different heights and exposure durations were quantified.

\section{Methods}

Approach: A lab-based simulation was used to evaluate the effect of lift-assist handle on the kinematics of the trunk and shoulder joints. An optical motion capture system was used to record three-dimensional locations of retro-reflective markers placed on anatomical landmarks of the participant's body. Joint kinematics were computed using the marker data.

Participants: A convenient sample of seven healthy engineering graduate and undergraduate male students was used for data collection. The age, height, weight of the participants was 23.5 $( \pm 3.2)$ years, $172( \pm 3.7) \mathrm{cm}$, and $66.2( \pm 4.6) \mathrm{kg}$, respectively. Potential participants were excluded if they had current or previous musculoskeletal complaints or had any physical disabilities or conditions that would affect their ability to perform the tasks. Additionally, the Physical Activity Readiness Questionnaire (PAR-Q, Canadian Society for Exercise Physiology) was used to screen potential participants for cardiac and other health problems (e.g., dizziness, chest pain, heart problems, etc.).

Optical motion capture system: Vicon motion capture system (Vicon Motion Labs, Oxford, UK) was used to capture the body motion during simulated lifting tasks. This system consists of eight optical cameras (MX-Series) with infrared strobes (Figure 1 (a)) that emit pulses of infrared light at high frequencies. The infrared light reflects off of small, round retro-reflective markers (Figure 1(b)) and is captured by the cameras in the Vicon system. When multiple cameras capture reflections from the markers, the location of the marker in three-dimensional space can be determined by the Vicon Nexus software.

Figure 1. Vicon MX camera with infrared strobe lights; (b) $14 \mathrm{~mm}$ (0.55in) Retro-reflective markers

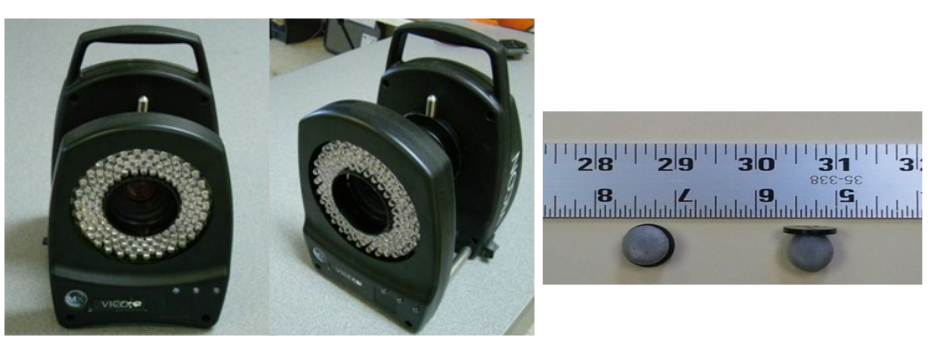

(a)

(b)

Motion analysis software: Vicon Nexus 1.5.1 (Vicon Motion Labs, Oxford, UK) software was used to track the markers affixed to the participants (Figure 2(a)) and analyze the marker data from the Vicon cameras. The software tracks the location of the markers by using raw data from the camera system. A three-dimensional representation of the markers is displayed on screen throughout the capture (Figure 2(b)). The marker data was captured at a rate of 100 frames per second $(100 \mathrm{~Hz})$.

Kinematic computation software: Visual 3D (C-Motion Inc, Germantown, MD, USA) software was used for analysis and modeling of three-dimensional marker data (Figure 2(c)). By capturing a static-posture trial, the software can create a human model and apply it to dynamic capture data from .c3d files based on the trajectories (locations) of calibration and cluster markers. For example, for tracking the location of the trunk, the following four markers are used in this research: one marker on the $\mathrm{C7}$, one 
marker on the T10, and two markers on both side of the back. The software can then determine frame-by-frame joint angles based on outputs from the model.

Figure 2. (a) The custom marker set affixed to a participant. The marker set was symmetrical right to left. (b) Real-time 3D Perspective view in Nexus. (c) kinematic model developed in visual 3D.

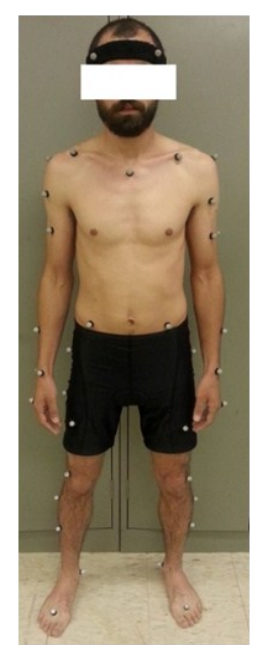

(a)

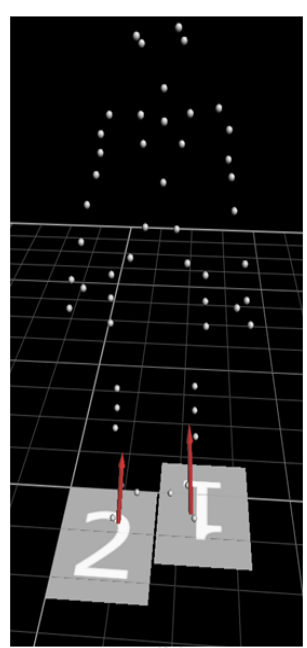

(b)

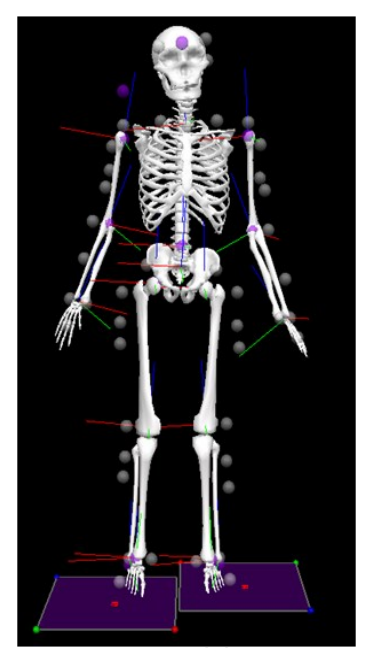

(c)
Lift-assist device: The lift-assist device evaluated in this study provides a padded handle for the user to grasp. The handle attaches to the construction block with two connected vertical prongs that fit into holes in the construction block(19 kg). The friction between the two prongs and the block provides a secure connection (Figure 3).

Figure 3. (a) Lift-assist handle (b) Block with the lift-assist handle.

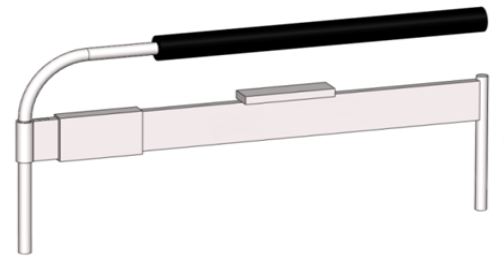

(a)

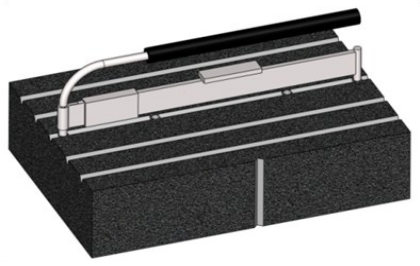

(b)
Experimental design: A three-factor replicated block design was used in this research. Factor 1, handle condition, was treated at two levels: 1) with handle and 2) without handle. Factor 2, direction of motion, was treated at two levels: 1) lifting and 2) lowering. Factor 3, lifting/lowering height, was treated at two levels: 1) 17" and 2) 29". The heights approximately represent second and fourth rows of the blocks when delivered to a construction site on a pallet (Figure 4). Human participants were treated as blocks. Individual participant performed 24 experimental trials $(2$ handle $\times 2$ directions $\times 2$ heights $\times 3$ repetitions) in random order. A rest period of 45 to 60 seconds was provided between the experimental trials to mitigate fatigue.

Data collection: Upon arrival, the participants were familiarized with the experimental setup, procedures, and equipment. In order to accurately determine the joint angles, the retro-reflective markers must follow the anatomical landmark on which they were placed. Therefore, the participant was instructed to change into tight-fitting, spandex shorts and remove their shirt. The spandex shorts also helped ensure that the markers were not hidden during the capture. Fifty one retro-reflective markers were affixed to specific landmarks of the body (Figure 2 (a)) to allow accurate modeling of the dynamic trials within Visual 3D.

Prior to actual data collection, a 5-second static posture trial with the participant in the standard anatomical position was captured for use in the analysis. Subsequently the participant performed the experimental tasks under different conditions of handle, height and direction.

Figure 4: Schematic representation of the block lifting heights.

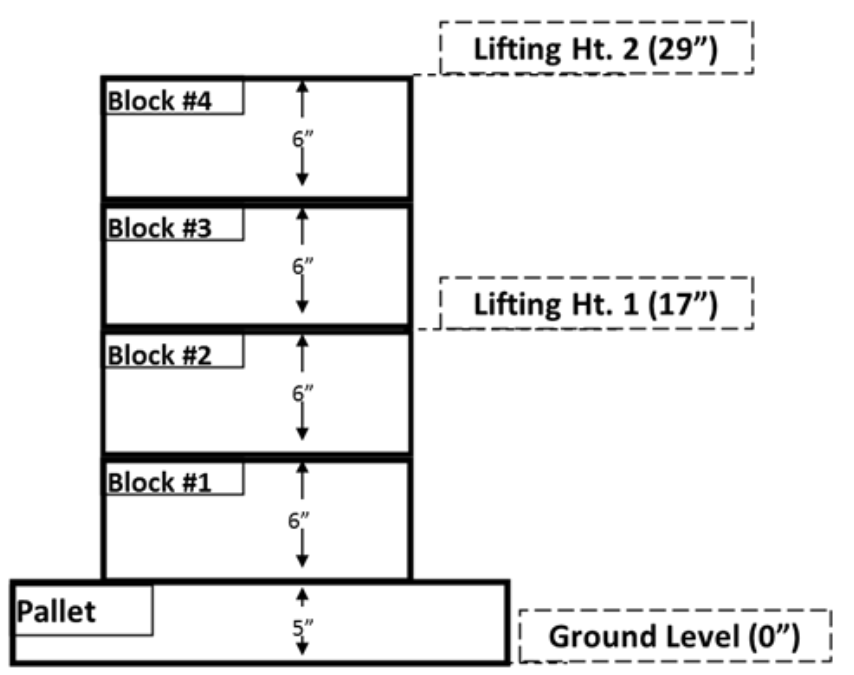

Data processing: Each experimental trial was processed by first labeling each marker with its unique identifier (i.e. RELB for right elbow). Gaps in the marker data were filled using the built-in gap-filling algorithms in Vicon Nexus and the data were exported for further processing.

The static trial was used to create a model of the participant in Visual3D. Each body segment is modeled based on markers on the endpoints of the segment as well as additional tracking markers on each segment. Each segment is assigned a local $X Y Z$ coordinate frame that follows the right-hand rule with the $Z$-axis directed proximally along the long axis of the segment and the $\mathrm{Y}$-axis directed anteriorly. The resulting model was applied to each dynamic trial to produce a fully-modeled representation of the participant performing each task (Figure 2 (c)). In-built functionality of the Visual3D software allowed the computation of frame-by-frame, three-dimensional anatomical joint angles by calculating Euler rotations between the local coordinate frames of the relevant segments. Angle data were used to determine the ranges of motion (ROM).

Statistical analysis: A general linear ANOVA was performed to evaluate the effect of handle, lifting height, and lifting direction on the motions of trunk and shoulder joints. Handle condition, lifting height, and lifting direction were treated as fixed effects and subjects as a random factor. The dependent variables were 
range of motion (ROM) of flexion-extension, lateral bending, and rotation for the trunk joint, and flexion-extension, abductionadduction, and rotation of the shoulder joint. In addition to the joint ROM the effect of abovementioned independent variables was also tested on the block holding duration. This duration was defined as the time the participant started from neutral standing posture to lift/lower the block until the time participant returned to neutral standing posture. Significance level was set to $95 \%$. The adequacy of the linear model was confirmed by normal probability plots of the residuals between the actual and fitted value. Minitab 16 software (Minitab Inc., Pennsylvania, USA) was used to perform the statistical analysis.

\section{Results}

Statistically no difference was found in the joint angles for lifting and lowering motions and therefore the data were pooled for the analysis. Similarly, no difference was found in the left and right side angles for shoulder joint and therefore data were also pooled for the analysis.

The lifting tasks required a much higher motion of the trunk in the flexion-extension direction $\left(48-89^{\circ}\right)$ compared to the lateral bending $\left(7-23^{\circ}\right)$ and trunk rotation $\left(10-23^{\circ}\right)$. A significant main effect of handle on the trunk joint motion was observed. Use of handle significantly reduced the trunk flexion, lateral bending and rotation ROM (All P<0.05) (Figure 5(a), Table I).

A significant two factor interactions effect (height and handle) was observed for shoulder abduction-adduction (Figure 6). For the without handle condition no change in shoulder abductionadduction was observed with the increase in the height. However, for the with handle condition, increase in the height increased shoulder abduction-adduction.
The average block holding duration, that is, the time the participant started from neutral standing posture to lift/lower the block until the time participant returned to neutral standing posture, was significantly reduced (decreased by $26 \%$ ) while the task was performed using handle: mean duration of $5.44 \mathrm{~s}$ for using handle compared to $6.83 \mathrm{~s}$ for without using handle (Table I\& Figure 6).

Figure 5. ROMs for different height and handle conditions: (a) Trunk joint; (b) Shoulder joint. Error bars represent standard errors and asterisk (*) indicates a statistically significant difference.
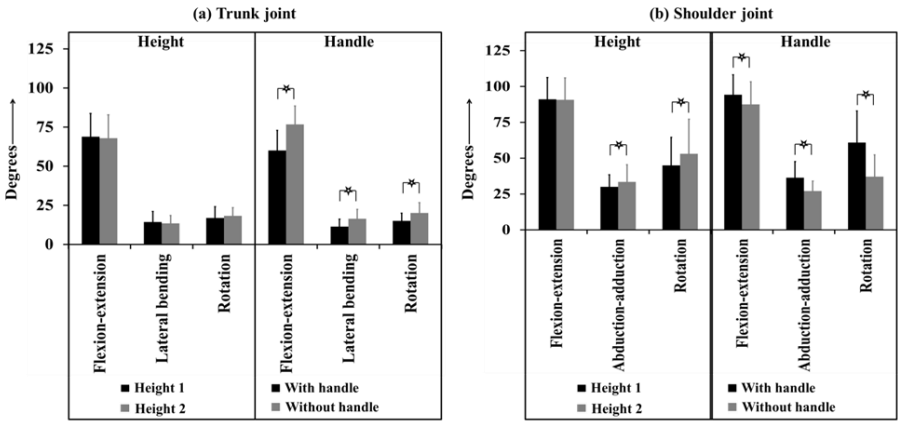

Figure 6: Mean block holding duration (seconds) for using handling tool vs without using handling tool.

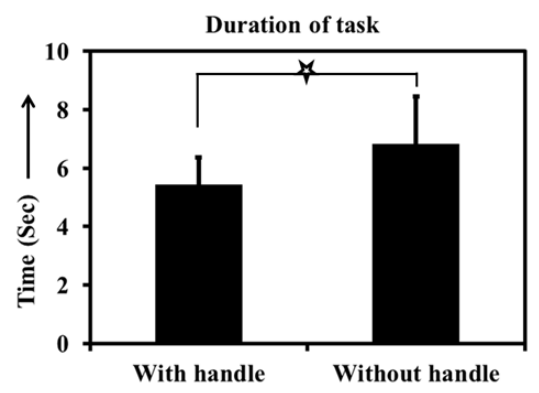

Table I Results of statistical analysis. Asterisk (*) denotes statistical significance.

\begin{tabular}{|c|c|c|c|c|c|c|c|c|c|}
\hline & & \multicolumn{3}{|c|}{ Height } & \multicolumn{4}{|c|}{ Handle } & \multirow{2}{*}{$\begin{array}{c}\text { Height } \times \text { Handle } \\
\text { p-value }\end{array}$} \\
\hline & & Height 1 & Height 2 & p-value & With & & nout & p-value & \\
\hline \multirow{3}{*}{$\begin{array}{c}\text { ROM } \\
\text { (degrees) }\end{array}$} & $\begin{array}{l}\text { Trunk flexion- } \\
\text { extension }\end{array}$ & $\begin{array}{l}68.83 \\
(14.81)\end{array}$ & $\begin{array}{l}67.84 \\
(14.99)\end{array}$ & 0.327 & $\begin{array}{c}60.02 \\
(12.89)\end{array}$ & 76.64 & $(11.75)$ & $<0.001^{*}$ & 0.10 \\
\hline & $\begin{array}{l}\text { Trunk lateral } \\
\text { bending }\end{array}$ & $\begin{array}{l}14.33 \\
(6.71)\end{array}$ & $\begin{array}{l}13.44 \\
(5.06)\end{array}$ & 0.24 & $\begin{array}{l}11.40 \\
(4.71)\end{array}$ & 16.37 & $(6.02)$ & $<0.001^{*}$ & 0.12 \\
\hline & Trunk rotation & $16.81(7.29)$ & $\begin{array}{l}18.19 \\
(5.25)\end{array}$ & 0.17 & $\begin{array}{l}15.00 \\
(4.93)\end{array}$ & 20.01 & $(6.68)$ & $<0.001^{*}$ & 0.10 \\
\hline \multirow[t]{3}{*}{ Mean (SD) } & $\begin{array}{l}\text { Shoulder flexion- } \\
\text { extension }\end{array}$ & $\begin{array}{l}91.03 \\
(15.15)\end{array}$ & $\begin{array}{l}90.68 \\
(15.31)\end{array}$ & 0.172 & $\begin{array}{l}94.20 \\
(13.92)\end{array}$ & 87.51 & (14.99) & $<0.001^{*}$ & 0.10 \\
\hline & $\begin{array}{c}\text { Shoulder abduction } \\
\text {-adduction }\end{array}$ & $29.94(8.43)$ & $\begin{array}{c}33.35 \\
(12.03)\end{array}$ & $0.003^{*}$ & $\begin{array}{c}36.29 \\
(11.38)\end{array}$ & 27.00 & $(6.97)$ & $<0.001^{*}$ & $<0.001^{*}$ \\
\hline & Shoulder rotation & $\begin{array}{l}44.96 \\
(19.54)\end{array}$ & $\begin{array}{l}53.04 \\
(24.16)\end{array}$ & $<0.001^{*}$ & $\begin{array}{l}60.89 \\
(21.97)\end{array}$ & 37.12 & $(15.18)$ & $<0.001^{*}$ & 0.61 \\
\hline \multicolumn{2}{|c|}{$\begin{array}{l}\text { Block holding duration(Sec) } \\
\qquad \text { Mean(SD) }\end{array}$} & $6.16 \quad(1.61)$ & $\begin{array}{c}6.11 \\
(1.37)\end{array}$ & 0.78 & $\begin{array}{c}5.44 \\
(0.93)\end{array}$ & 6.83 & $(1.62)$ & $<0.001^{*}$ & 0.463 \\
\hline
\end{tabular}


In this study the effect of a lift-assist device on the kinematics of trunk and shoulder joints was studied. Use of the device was found to decrease trunk flexion. When the participant performed the task without the block, they had to reach down to the ground to grasp the base of the construction block. However, due to the location of the handle with the device secured to the construction block, the participant did not have to flex their trunk as much to grasp the block. The relationship between increased trunk flexion and increased risk of low back musculoskeletal disorders has been well-established [16, 31-32], suggesting a benefit from the use of the handle with regard to low back health.

While the increased grasping height provided by the handle of the device decreased trunk flexion, it also resulted in an increase in flexion of the shoulder. When placing the block in its final location, the participant must lift their arms several inches higher when using the handle compared to grasping the block at the base. Research has shown that lifting height, especially at or above shoulder level, plays a significant role in the development of shoulder musculoskeletal disorders. Beach et al. (2012) found a significant increase in shoulder injury claims related to lifting more than $15 \mathrm{~kg}$ over shoulder height for more than 15 minutes per day[33]. This is notable because these criteria were met by the participants in this research when the handle was used. In a prospective cohort study of 1,081 respondents, Harkness et al. (2003) found an increased prevalence of new onset shoulder pain due to working with hands at or above shoulder level, even with loads of less than $9.1 \mathrm{~kg}[34]$.In our research, peak shoulder flexion angle was found to be slightly above $90^{\circ}$ with use of the handle and slightly below $90^{\circ}$ without the handle. This suggest that use of the handle could result in more time spent with the upper arms above shoulder height and therefore may increase the risk of shoulder musculoskeletal disorders.

Effect of lifting height was less substantial, with significant differences of only rotation and abduction at the shoulders. These differences are due to the posture used for the lift. With or without the handle, the participants kept the construction block near the body during the tasks, which relies predominantly on shoulder abduction to raise the block and rotation to keep it near the body. This posture, along with the relatively small difference between the lifting heights, is also responsible for the lack of significance of lifting height on shoulder and trunk flexion.

While trunk flexion and the time taken to complete the task were reduced with use of the handle, suggesting decreased strain on the back and increased productivity, respectively, the increase in shoulder flexion and accompanying potential increased risk of shoulder injury must be considered. If the additional strain on the shoulder from use of the device causes a proportional increase in musculoskeletal disorders of the shoulder and decrease in musculoskeletal disorders of the back, use of the device may not provide an overall benefit, considering musculoskeletal disorders of the shoulder, in general, require significantly more time away from work than musculoskeletal injuries of the lower back[1]. On the other hand, if the increased risk is insignificant, the benefit to productivity may make implementation worthwhile. However, the increase in productivity may increase the work throughout the day, potentially increasing the cumulative strain and having an overall negative effect. These findings emphasize the need for an in-depth, multi-faceted analysis prior to implementation of assistive devices. Ideally, on-site collection of electromyography data, posture/motion data, and subjective ratings of discomfort along with subsequent biomechanical modeling to evaluate joint strain and cost-benefit analysis should be performed to make an informed decision on use of assistive devices.

This study had several limitations. First, the participants were male students enrolled at West Virginia University. None of the participants had any experience working with construction block, and were likely less physically active than experienced construction workers. Therefore, the lifting technique and physical characteristics of the participants may not be representative of the target population. Additionally, this research was performed in a laboratory, which is not representative of the environment in which this type of work is usually performed. Environmental factors such as temperature and walking surface as well as effects of fatigue could result in substantially different postures compared to the laboratory environment. Finally, only two lifting heights were used in this research and all lifting was done from ground level. At real work sites, the origin and destination positions of the block will be much more variable. While it seems likely that effect of the handle could remain consistent irrelevant of height, our limitation to only two lifting heights does not allow this conclusion to be made.

\section{Conclusion}

This research suggests that this lifting device could be beneficial in terms of productivity and lower back health. On the other hand, use of the handle resulted in shoulder flexion angles of greater than $90^{\circ}$ while they remained below $90^{\circ}$ with use of the handle, suggesting more time working above shoulder height, a risk factor for shoulder musculoskeletal disorders, when the handle is used. The findings of our research emphasize the need for in-depth analysis of assistive devices, including the one in this research, before implementing their use to ensure that they serve their intended purpose and have no unintended consequences that could negate their intended benefit.

\section{References}

1. BLS. Bureau of labor statistics. "Nonfatal Occupational Injuries and IIInesses requiring days away from work, 2012". 2013 [cited 2014 July 15]; Available from: http://www.bls.gov/ news.release/pdf/osh2.pdf.

2. Van der Molen H, Veenstra S, Sluiter J, Frings-Dresen M. World at work: Bricklayers and bricklayers' assistants. Occupational and environmental medicine. 2004;61(1):89-93.

3. Schneider S, Susi P. Ergonomics and construction: a review of potential hazards in new construction. American Industrial Hygiene Association. 1994;55(7):635-49. 
4. Spielholz P, Davis G, Griffith J. Physical risk factors and controls for musculoskeletal disorders in construction trades. Journal of construction engineering and management. 2006;132(10):1059-68.

5. Hess JA, Kincl L, Amasay T, Wolfe P. Ergonomic evaluation of masons laying concrete masonry units and autoclaved aerated concrete. Applied ergonomics. 2010;41(3):477-83.

6. BLS. Bureau of labor statistics. "Incidence rates of nonfatal occupational injuries and illnesses by industry and case type, 2012". 2014 [cited 2014 July 17]; Available from: http:// www.bls.gov/iif/oshwc/osh/os/ostb3581.pdf.

7. BLS. Bureau of labor statistics. "Industry by event or exposure, 2012". 2013 [cited 2014 July 17]; Available from: http://www.bls.gov/iif/oshwc/cfoi/cftb0268.pdf.

8. CPWR CfCRaT. Chart book: Fatal and Nonfatal Injuries. 2012 [cited 2014 July 17]; Available from: www.cpwr.com/ publications/chart-book-fatal-and-nonfatal-injuries.

9. Cook TM, Rosecrance JC, Zimmermann CL. Work-related musculoskeletal disorders in bricklaying: a symptom and job factors survey and guidelines for improvements. Applied occupational and environmental hygiene.1996;11(11):1335-9.

10. Entzel P, Albers J, Welch L. Best practices for preventing musculoskeletal disorders in masonry: stakeholder perspectives. Applied ergonomics. 2007;38(5):557-66.

11. Holmström E, Moritz U, Engholm G. Musculoskeletal disorders in construction workers. Occupational medicine (Philadelphia, Pa). 1994;10(2):295-312.

12. Marras WS, Lavender SA, Leurgans SE, Rajulu SL, Allread WG, Fathallah FA, et al. The Role of Dynamic ThreeDimensional Trunk Motion in Occupationally-Related Low Back Disorders: The Effects of Workplace Factors, Trunk Position, and Trunk Motion Characteristics on Risk of Injury. Spine. 1993;18(5):617-28.

13. Latza U, Karmaus W, Stürmer T, Steiner M, Neth A, Rehder $U$. Cohort study of occupational risk factors of low back pain in construction workers. Occupational and environmental medicine. 2000;57(1):28-34.

14. Kingma I, van Dieën JH. Lifting over an obstacle: effects of one-handed lifting and hand support on trunk kinematics and low back loading. Journal of biomechanics. 2004;37(2):249-55.

15. Hoozemans MJ, Kingma I, de Vries WH, van Dieën JH. Effect of lifting height and load mass on low back loading. Ergonomics. 2008;51(7):1053-63.

16. Hoogendoorn WE, Bongers PM, de Vet HC, Douwes M, Koes BW, Miedema MC, et al. Flexion and rotation of the trunk and lifting at work are risk factors for low back pain: results of a prospective cohort study. Spine. 2000;25 (23):3087-92.

17. Holmström E, Lindell J, Moritz U. Low back and neck/ shoulder pain in construction workers: occupational workload and psychosocial risk factors. Spine. 1992;17(6):663-71.

18. Granata KP, Marras WS. Relation between spinal load factors and the high-risk probability of occupational low-back disorder. Ergonomics. 1999;42(9):1187-99.

19. Nimbarte AD, Aghazadeh F, Ikuma LH, Harvey CM. Neck disorders among construction workers: understanding the physical loads on the cervical spine during static lifting tasks. Industrial health. 2010;48(2):145-53.

20. Grooten WJA, Mulder M, Josephson M, Alfredsson L, Wiktorin $C$. The influence of work-related exposures on the prognosis of neck/shoulder pain. European spine journal. 2007;16(12):2083-91.
21. Miranda H, Punnett L, Viikari-Juntura E, Heliövaara M, Knekt P. Physical work and chronic shoulder disorder. Results of a prospective population-based study. Annals of the rheumatic diseases. 2008;67(2):218-23.

22. Palmer KT, Smedley J. Work relatedness of chronic neck pain with physical findings-a systematic review. Scandinavian journal of work, environment \& health. 2007:165-91.

23. Chowdhury SK, Nimbarte AD, Jaridi M, Creese RC. Discrete wavelet transform analysis of surface electromyography for the fatigue assessment of neck and shoulder muscles. Journal of Electromyography and Kinesiology. 2013;23(5):995-1003.

24. Chaffin DB, PARK KS. A longitudinal study of low-back pain as associated with occupational weight lifting factors. The American Industrial Hygiene Association Journal. 1973;34 (12):513-25.

25. Stürmer T, Luessenhoop S, Neth A, Soyka M, Karmaus W, Toussaint $\mathrm{R}$, et al. Construction work and low back disorder: preliminary findings of the Hamburg construction worker study. Spine. 1997;22(21):2558-63.

26. Van Dieen $\mathrm{JH}$, Toussaint HM. Evaluation of the probability of spinal damage caused by sustained cyclic compression loading. Human Factors: The Journal of the Human Factors and Ergonomics Society. 1997;39(3):469-80.

27. Luttmann A, Jäger M, Laurig W. Task analysis and electromyography for bricklaying at different wall heights. International Journal of Industrial Ergonomics. 1991;8(3):247-60.

28. Anton D, Rosecrance J, Gerr F, Merlino L, Cook T. Effect of concrete block weight and wall height on electromyographic activity and heart rate of masons. Ergonomics. 2005;48 (10):1314-30.

29. Van Der Molen $H$, Kuijer $P$, Hopmans $P$, Houweling $A$, Faber G, Hoozemans $M$, et al. Effect of block weight on work demands and physical workload during masonry work. Ergonomics. 2008;51(3):355-66.

30. 30. Faber G, Kingma I, Kuijer $P$, Van der Molen $H$, Hoozemans $M$, Frings-Dresen $M$, et al. Working height, block mass and one-vs. two-handed block handling: the contribution to low back and shoulder loading during masonry work. Ergonomics. 2009;52(9):1104-18.

31. Schultz A, Andersson G, Haderspeck K, Örtengren R, Nordin M, Björk R. Analysis and measurement of lumbar trunk loads in tasks involving bends and twists. Journal of biomechanics. 1982;15(9):669-75.

32. Potvin J, McGill S, Norman R. Trunk muscle and lumbar ligament contributions to dynamic lifts with varying degrees of trunk flexion. Spine. 1991;16(9):1099-107.

33. Beach J, Senthilselvan A, Cherry N. Factors affecting workrelated shoulder pain. Occupational medicine. 2012.

34. Harkness E, Macfarlane G, Nahit E, Silman A, McBeth J. Mechanical and psychosocial factors predict new onset shoulder pain: a prospective cohort study of newly employed workers. Occupational and environmental medicine. 2003;60(11):850-7. 